\title{
Evaluation of Nutritional Status of Patients with Depression
}

\author{
Gülşah Kaner, ${ }^{1}$ Meltem Soylu, ${ }^{1}$ Nimet Yüksel, ${ }^{2}$ Neriman Inanç, \\ Dilek Ongan, ${ }^{3}$ and Eda Başmısırlı ${ }^{1}$ \\ ${ }^{1}$ Department of Nutrition and Dietetics, Faculty of Health Sciences, Nuh Naci Yazgan University, 38170 Kayseri, Turkey \\ ${ }^{2}$ Kayseri Education and Research Hospital, 38170 Kayseri, Turkey \\ ${ }^{3}$ Department of Nutrition and Dietetics, Faculty of Health Sciences, Izmir Kâtip Çelebi University, 35620 Izmir, Turkey
}

Correspondence should be addressed to Gülşah Kaner; dytgulsahk@gmail.com

Received 13 April 2015; Revised 6 August 2015; Accepted 11 August 2015

Academic Editor: Adair Santos

Copyright (c) 2015 Gülşah Kaner et al. This is an open access article distributed under the Creative Commons Attribution License, which permits unrestricted use, distribution, and reproduction in any medium, provided the original work is properly cited.

\begin{abstract}
Aims and Objectives. Our goal was to determine nutritional status, body composition, and biochemical parameters of patients diagnosed with depression based on DSM-IV-TR criteria. Methods. A total of 59 individuals, aged 18-60 years admitted to Mental Health Centre of Kayseri Education and Research Hospital, were included in the study. The participants were randomly assigned to two groups; depression group $(n=29)$ and control group $(n=30)$. Anthropometric measurements, some biochemical parameters, demographic data, and 24-hour dietary recall were evaluated. Results. $65.5 \%$ of depression and $60.0 \%$ of control group were female. Intake of vitamins $\mathrm{A}$, thiamine, riboflavin, $\mathrm{B} 6$, folate, $\mathrm{C}, \mathrm{Na}, \mathrm{K}, \mathrm{Mg}, \mathrm{Ca}, \mathrm{P}, \mathrm{Fe}, \mathrm{Zn}$, and fibre $(p<0.05)$ were lower in depression group. Median levels of body weight, waist circumference, hip circumference, waist-to-hip ratio $(p<0.05)$ were significantly higher in depression group. Fasting blood glucose levels, serum vitamins B12, and folic acid $(p<0.05)$ in depression group were lower than controls. Serum insulin and HOMA levels of two groups were similar. Conclusion. Some vitamin B consumption and serum vitamin B12 and folic acid levels were low while signs of abdominal obesity were high among patients with depression. Future research exploring nutritional status of individuals with depression is warranted.
\end{abstract}

\section{Introduction}

Depression alone accounts for $4.3 \%$ of the global burden of disease and is among the largest single causes of disability worldwide $(11 \%$ of all years lived with disability globally), particularly for women [1]. Studies about associations between diet and depression have primarily focused on single nutrients or foods. Recently, dietary patterns representing a combination of foods have attracted more interest than an individual nutrient. Depression is a serious effective illness with a high lifetime prevalence rate in which diet has been suggested as one modifiable factor [2].

An association between diet and depression has now been confirmed in prospective and epidemiological studies. For example, in elderly men and women, consumption of fish, vegetables, olive oil, and cereals was negatively correlated with severity of depressive symptoms [3]. The benefits from fish and olive oil intake remained significant even when adjusted for confounders such as age, sex, educational status,
BMI, and physical activity level as well as the presence of a number of medical conditions [4]. In a prospective study, after adjusting for sex, age, smoking status, BMI, physical activity levels, and employment status, adherence to a Mediterranean diet including high levels of vegetables, fruits, nuts, cereals, legumes, and fish, moderate alcohol intake, and low amount of meat or meat products and whole-fat dairy intake was protective against development of depression [4]. In a study by Jacka et al. [5], consuming a "traditional" diet containing vegetables, fruits, meat, fish, and whole grains was also associated with a $35 \%$ reduced risk of depression or dysthymia. Researches about diet of adolescents [5] and of the community-dwelling elderly with low socioeconomic level [6] have also provided evidence for an association between diet quality and depression. Depressive symptoms are also positively associated with consumption of sweets [7]. Similarly, high consumption of fast food and processed pastries is associated with an increased risk for depression up to 6 years later [8]. In a randomised-controlled trial, six 
days on a low protein diet significantly decreased depressive symptoms in patients with type 2 diabetes mellitus [9] and, in another randomised study about overweight and obese individuals, those who were placed on an energy-restricted, low-fat diet for one-year experienced greater improvements in mood compared to participants on an energy-restricted, low-carbohydrate diet [10]. These changes were independent of weight loss. PUFAs, particularly omega-3 essential fatty acids (EFA), have received significant attention in relation to depression. In a meta-analysis of 14 studies comparing the levels of PUFAs between depressed patients and control subjects, levels of eicosapentaenoic acid (EPA), docosahexaenoic acid (DHA), and total n-3 EFA were significantly lower in depressed patients than controls. There was no significant change in arachidonic acid (AA) or total n-6 PUFAs [11]. A meta-analysis of 15 clinical trials about effects of EPA supplementation in depressed populations revealed beneficial effects from fish oil containing high levels of EPA [12]. Other investigations about relationship between nutrients and depression have also demonstrated a role of folate $[13,14], \mathrm{Zn}[15-17], \mathrm{Fe}[18,19]$, vitamin $\mathrm{B}_{6}[20-22]$, and vitamin $\mathrm{B}_{12}[21,23]$.

Obesity is associated with an increased risk of mental illness however; evidence linking BMI to mental illness is inconsistent [24]. Whether obesity also predicts psychiatric disorders such as depression has not been established. Thus far, population-based studies of association between obesity and depression have yielded inconsistent results [25]. Some studies found an association [26-28], while others did not [29-31]. Depressive symptoms may contribute to abdominal obesity through consumption of diets with high energy density [32]. Grossniklaus et al. [32] have determined that depressive symptoms and dietary energy density were associated with elevated waist circumference. Among overweight and obese U.S. adults, high waist circumference or abdominal obesity was significantly associated with increased likelihoods of having major depressive symptoms or moderateto-severe depressive symptoms. Zhao et al. [33] stated that mental health status should be monitored and evaluated in adults with abdominal obesity, particularly in those who are overweight.

These results suggest that healthy dietary pattern is significantly associated with major depression in adults. Further studies are needed to confirm them, however. In addition, to the best of our knowledge, there is no study of its kind in our country to evaluate nutritional intake of patients with depression. Therefore, the present study was conducted to determine nutritional status, body composition, and selected biochemical parameters of patients diagnosed with depression based on DSM-IV-TR criteria and to compare their data those of a control group.

\section{Methods}

This randomized controlled study was performed at our Mental Health Centre Clinic of Kayseri Education and Research Hospital of Medicine, a tertiary referral centre in Turkey.

Forty-two inpatients diagnosed with major depression in accordance with Diagnostic and Statistical Manual of
Mental Disorders, Fourth Edition (DSM-IV-TR), who are on antidepressant medication and thirty-two normal healthy volunteers aged between 18 and 60 were studied between 2009 and 2010. Of 74 subjects, 13 patients and 2 healthy subjects had missing information thus data of 59 participants (29 patients in depression group and 30 healthy volunteers in controls) were used.

Demographic characteristics like age, gender, family status (married, divorced, and widowed), financial status (average annual income during the past three years), smoking habits, alcohol consumption, and occupational status as well as education level were obtained with questionnaire by faceto-face interview. There were no differences between groups across race/ethnicity.

Food consumption frequency, energy, and nutrient intake by 24-hour dietary recall were determined. Daily energy expenditure and physical activity levels were calculated. Height, body weight, waist circumference, hip circumference, BMI, and waist-to-hip ratio were also determined. Selected biochemical parameters were evaluated (fasting blood glucose, folate, vitamin $\mathrm{B}_{12}$, and insulin).

Exclusion criteria were derived as follows: (1) serious mental illness (e.g., a psychotic disorder, bipolar disorder, posttraumatic stress disorder, schizophrenia, anxiety disorders, dementia, or bulimia), (2) recent initiation or dose adjustment of thyroid medications, and (3) weight loss medication or treatment, bariatric surgery, diabetes, and pregnancy.

All participants provided written informed consent, and the protocol was approved by the institutional review boards of the participating centers, in accordance with the Declaration of Helsinki. The institutional review board of the Ethics Committee of Faculty of Medicine in Erciyes University (Kayseri, Turkey) approved the study protocol on November 5,2009 . This trial was registered with number 2009/130.

\subsection{Data Collection}

2.1.1. Preparation and Implementation of the Questionnaire. The questionnaire was designed in a manner understandable for individuals and was based on literature review $[6,34$, 35]. Comprehensibility of questions in the questionnaire was tested on 20 individuals, necessary adjustment was made accordingly, and questionnaire was finalized. The questionnaire included an overview of individual's eating habits, anthropometric measurements, food consumption frequency, energy and nutrient intake, and physical activity level with 24-hour recall. The questionnaire took approximately 45 minutes to administer for each participant.

2.1.2. Anthropometric Measurements. Anthropometric measurements were determined according to WHO criteria [36]. Body weight, height, waist, and hip circumferences were measured and BMI was calculated (BMI = body weight $(\mathrm{kg}) /$ height $\left.\left(\mathrm{m}^{2}\right)\right)$. All subjects were weighed while wearing light clothing and being without shoes, using a calibrated digital flat scale (Seca-803, USA). Standing height was measured without shoes to the nearest $0.5 \mathrm{~cm}$ with a measuring tape. All anthropometric measurements were measured three times 
and mean values were obtained. BMI values were evaluated using WHO classification which shows that a BMI less than $20.0 \mathrm{~kg} / \mathrm{m}^{2}$ is classified as underweight, between 20.0 and $24.9 \mathrm{~kg} / \mathrm{m}^{2}$ is defined as normal weight, between 25.0 and $29.9 \mathrm{~kg} / \mathrm{m}^{2}$ as overweight, between 30.0 and $34.9 \mathrm{~kg} / \mathrm{m}^{2}$ as 1st-degree obesity, and between 35.0 and $39.9 \mathrm{~kg} / \mathrm{m}^{2}$ as 2nddegree obesity, and BMI higher than $40 \mathrm{~kg} / \mathrm{m}^{2}$ is classified as 3rd-degree (morbid) obesity [37].

2.1.3. Assessment of Food Consumption. Nutritional behaviour of participants was determined by food consumption frequency and 24-hour dietary recall. Nutrient Database (BeBiS, Ebispro for Windows, Germany; Turkish Version/BeBiS 7) was used to determine energy and nutrient intake; results were compared to Dietary Guidelines for Turkey [38]. Lower than $67 \%$ of recommended daily intake of energy and nutrients was evaluated as inadequate. Volumes and portion sizes were estimated with 2-dimensional food models and with a portion size picture booklet including 120 photographs of foods, each with 3-5 different portion sizes [38, 39].

2.1.4. Assessment of Energy Expenditure. The participants recorded their activity level over a 24-hour period. Closed attention was given that activity duration equaled 24 hours. To determine energy expenditure per activity type, physical activity level (PAL) was calculated. PAL and basal metabolic rate (BMR) were multiplied and daily energy expenditure was obtained [37]. BMR was calculated according to the following formulas based on age and gender [37]:

For men aged $19-30$ years, $15.3 \times$ body weight $(\mathrm{kg})+$ $679 \mathrm{kcal}$.

For women aged 19-30 years, $14.7 \times$ body weight $(\mathrm{kg})$ $+496 \mathrm{kcal}$.

For men aged 31-60 years, $11.6 \times$ body weight $(\mathrm{kg})+$ $879 \mathrm{kcal}$.

For women aged $31-60$ years, $8.7 \times$ body weight $(\mathrm{kg})+$ 829 kcal.

For men aged $>60$ years, $13.5 \times$ body weight $(\mathrm{kg})+$ $487 \mathrm{kcal}$.

For women aged $>60$ years, $10.5 \times$ body weight $(\mathrm{kg})+$ $596 \mathrm{kcal}$.

\subsection{Assessment of Biochemical Parameters}

2.2.1. Sample Collection and Preparation. Venous blood samples were collected after overnight fasting. Blood samples were incubated for one hour at room temperature; sera were separated and then stored at $-20^{\circ} \mathrm{C}$ until biochemical analysis. Blood samples with anticoagulant were immediately centrifuged and plasmas were separated and stored at $-70^{\circ} \mathrm{C}$ until insulin analysis. In patients, HOMA-IR (Homeostasis Assessment Model of Insulin Resistance) method (fasting insulin $\mathrm{mU} / \mathrm{mL} \times$ fasting glucose $\mathrm{mmol} / \mathrm{L} / 22.5$ ) was used. In the HOMA-IR test, a minimum value of 2.5 was accepted as insulin resistance.
2.2.2. Biochemical Analysis. Serum fasting blood glucose, triglyceride (TG), total cholesterol (C), HDL-C, and LDL$\mathrm{C}$ concentrations were determined with kits by Architect c16000 autoanalyzer (Abbott Diagnostics, USA). Vitamin $B_{12}$ and folic acid concentrations were determined with Advia Centaur XP immunoassay system (Siemens, Germany) with kits by Advia Centaur XP immunoassay system.

2.3. Statistical Analysis. Data were analysed with SPSS version 15.0 (Inc., Chicago, IL, USA). Normal distribution of data was determined with Shapiro-Wilk test. Chi-square analysis was used to compare the difference of qualitative variables between groups and Mann Whitney $U$ test was used for quantitative data by showing median, $25 \%-75 \%$ percentages. $p<0.05$ was set as statistically significant.

\section{Results}

Mean ages of depression (36.82 \pm 1.86 years) and control (33.13 \pm 1.57 years) groups were similar $(p>0.05) .65 .5 \%$ of depression group and $60.0 \%$ of control group were females. Depression group that indicated that food consumption increased $(20.7 \%)$ during times of sadness was significantly higher compared with controls $(6.7 \%)(p<0.05)$. Controls who indicated no changes in food consumption while experiencing nervousness $(46.7 \%)$ or happiness $(73.3 \%)$ were found to be significantly higher compared to the depression group $(6.9 \%$ and $31.0 \%$, resp., $p<0.05)$. Between-meals consumption of depression group $(82.8 \%)$ was significantly lower than controls $(100 \%, p<0.05)$. Rate of night eating in depression group was $41.4 \%$ while it was $13.3 \%$ in controls $(p<0.05)$

Ratio of daily fresh fruit consumption was lower in depression group (13.8\%) than in controls (50.0\%). Daily consumption of fresh vegetables was $31.1 \%$ in depression group while it was $46.7 \%$ in controls. Of depression group, $65.4 \%$ consumed fish which was significantly lower than controls (83.3\%). Among depression group, 10.3\% of individuals were sedentary. Light physical activity levels were higher in depression group (86.2\%) compared with the controls (56.7\%). A statistical significance was found among physical activity levels between groups $\left(\chi^{2}=14.819, p<0.05\right)$. There was no difference between the groups in terms of smoking and alcohol consumption.

Although statistically insignificant, polyunsaturated fatty acids (PUFA) intake of controls [10.53 (8.29-13.91)g] was higher than of depression group [7.62 (5.82-12.49) g] $(z=$ $-1.933, p>0.05)$. Intakes of vitamins $\mathrm{A}(p<0.05)$, thiamine $(p<0.05)$, riboflavin $(p<0.05)$, vitamins $\mathrm{B}_{6}(p<0.05)$, folate $(p<0.05)$, vitamin $\mathrm{C}(p<0.05), \mathrm{Na}(p<0.05), \mathrm{K}$ $(p<0.05), \mathrm{Mg}(p<0.05), \mathrm{Ca}(p<0.05), \mathrm{P}(p<0.05), \mathrm{Fe}$ $(p<0.05), \mathrm{Zn}(p<0.05)$, and fibre $(p<0.05)$ were lower in depression group (Table 1). According to Dietary Guidelines for Turkey, intake of fibre, niacin, vitamins $\mathrm{B}_{6}, \mathrm{C}(p<0.05$ for each), and $\mathrm{Mg}(p<0.05)$ was lower in women with depression while intake of energy, fibre, vitamins $A, E, B_{6}$, and $\mathrm{C}(p<0.05$ for each), and folate $(p<0.05)$ were lower in men with depression. 
TABLE 1: Energy and nutrients consumption of depression and control groups.

\begin{tabular}{|c|c|c|c|c|}
\hline Energy and nutrients & $\begin{array}{c}\text { Depression group }(n=29) \\
\text { Median }(25 \% \mathrm{p}-75 \% \mathrm{p})\end{array}$ & $\begin{array}{l}\text { Control group }(n=30) \\
\text { Median }(25 \% \mathrm{p}-75 \% \mathrm{p})\end{array}$ & $Z$ & $p$ \\
\hline Energy (kcal) & 1535 (1322-1710) & $1498(1380-1784)$ & -0.121 & 0.910 \\
\hline $\mathrm{CHO}(\mathrm{g})$ & $210.2(162.5-239.9)$ & $181.8(163.5-220.1)$ & -1.183 & 0.240 \\
\hline $\mathrm{CHO} \%$ & $55.0(48.5-61.0)$ & $50.0(45.0-56.3)$ & -1.921 & 0.055 \\
\hline Fat (g) & $51.8(40.5-62.4)$ & $52.4(43.3-62.1)$ & -0.030 & 0.982 \\
\hline Fat $\%$ & $31.0(26.0-34.5)$ & $32.0(25.0-36.0)$ & -0.448 & 0.659 \\
\hline Protein (g) & $57.1(44.2-65.6)$ & $64.3(53.2-73.7)$ & -1.926 & 0.055 \\
\hline Protein \% & $14.0(12.5-16.5)$ & $17.0(14.0-21.3)$ & -2.419 & $0.015^{*}$ \\
\hline Cholesterol (mg) & $168.2(120.4-246.7)$ & $166.5(108.8-255.6)$ & -0.243 & 0.816 \\
\hline PUFA (g) & $7.62(5.8-12.5)$ & $10.53(8.3-13.9)$ & -1.933 & 0.053 \\
\hline Vitamin A $(\mu \mathrm{g})$ & $516.6(467.7-683.5)$ & $670.5(449.6-1249.6)$ & -2.017 & $0.044^{*}$ \\
\hline Vitamin E (mg) & $7.8(5.6-11.7)$ & $9.2(7.0-15.4)$ & -1.956 & 0.051 \\
\hline Thiamine (mg) & $0.5(0.4-0.7)$ & $0.7(0.6-0.9)$ & -2.889 & $0.003^{* *}$ \\
\hline Riboflavin (mg) & $0.8(0.7-1.0)$ & $1.1(0.9-1.3)$ & -3.754 & $<0.001$ \\
\hline Niacin (mg) & $8.6(6.83-11.43)$ & $10.8(7.3-13.3)$ & -1.433 & 0.154 \\
\hline Vitamin $B_{6}(\mathrm{mg})$ & $0.8(0.6-1.0)$ & $1.2(0.9-1.4)$ & -3.662 & $<0.001$ \\
\hline Vitamin $B_{12}(\mu \mathrm{g})$ & $2.4(1.3-4.3)$ & $2.5(1.4-3.6)$ & -0.190 & 0.854 \\
\hline Folate $(\mu \mathrm{g})$ & $193.4(149.8-268.3)$ & $261.8(220.4-318.6)$ & -3.214 & $0.001^{* *}$ \\
\hline Vitamin C (mg) & $45.1(21.6-70.3)$ & $97.1(40.3-191.9)$ & -3.214 & $0.001^{* *}$ \\
\hline $\mathrm{Na}(\mathrm{mg})$ & $2734.8(2159.0-3329.6)$ & $3289.0(2663.5-3810.9)$ & -1.971 & $0.049^{*}$ \\
\hline $\mathrm{K}(\mathrm{mg})$ & $1353.9(1083.6-1653.2)$ & $2063.9(1665.1-2545.4)$ & -4.533 & $<0.001$ \\
\hline $\mathrm{Mg}(\mathrm{mg})$ & $183.2(146.6-205.7)$ & $244.3(184.3-305.2)$ & -3.654 & $<0.001$ \\
\hline $\mathrm{Ca}(\mathrm{mg})$ & $367.9(295.8-508.6)$ & $592.7(457.4-814.5)$ & -4.351 & $<0.001$ \\
\hline $\mathrm{P}(\mathrm{mg})$ & $744.7(572.0-880.2)$ & $899.1(766.7-1081.2)$ & -3.108 & $0.002^{* *}$ \\
\hline $\mathrm{Fe}(\mathrm{mg})$ & $8.5(7.2-10.6)$ & $10.6(9.2-12.7)$ & -2.593 & $0.009^{* *}$ \\
\hline $\mathrm{Zn}(\mathrm{mg})$ & $8.3(7.2-10.4)$ & $10.1(8.3-11.3)$ & -2.320 & $0.020^{*}$ \\
\hline Fibre (g) & $13.3(9.7-19.6)$ & $21.5(15.7-24.8)$ & -3.131 & $0.001^{* *}$ \\
\hline
\end{tabular}

Median (25\%-75\%) represents median, 25th percentile and 75th percentile.

${ }^{*} p<0.05$ and $^{* *} p<0.01$.

TABLE 2: Anthropometric measurements of depression and control groups.

\begin{tabular}{|c|c|c|c|c|}
\hline Anthropometric measurements & $\begin{array}{l}\text { Depression group } \\
\qquad(n=29) \\
\text { Median } \\
(25 \% \mathrm{p}-75 \% \mathrm{p})\end{array}$ & $\begin{array}{l}\text { Control group } \\
(n=30) \\
\text { Median } \\
(25 \% \mathrm{p}-75 \% \mathrm{p}) \\
\end{array}$ & $Z$ & $p$ \\
\hline Height (m) & $1.63(1.60-1.71)$ & $1.63(1.57-1.73)$ & -0.083 & 0.937 \\
\hline Body weight (kg) & $75.1(64.7-88.6)$ & $66.8(62.2-79.0)$ & -2.229 & $0.025^{*}$ \\
\hline $\operatorname{BMI}\left(\mathrm{kg} / \mathrm{m}^{2}\right)$ & $28.96(24.37-33.46)$ & $25.06(22.08-27.26)$ & -2.699 & $0.006^{* *}$ \\
\hline Waist circumference $(\mathrm{cm})$ & $91.00(83.50-100.00)$ & $78.50(75.00-90.00)$ & -3.679 & $<0.001$ \\
\hline Hip circumference $(\mathrm{cm})$ & $105.00(100.00-115.00)$ & $100.50(93.75-93.75)$ & -2.778 & $0.005^{* *}$ \\
\hline Waist-to-hip ratio & $0.85(0.82-0.93)$ & $0.78(0.76-0.87)$ & -2.593 & $0.009^{* *}$ \\
\hline
\end{tabular}

Median (25\%-75\%) represents median, 25th percentile and 75th percentile.

${ }^{*} p<0.05$ and $^{* *} p<0.01$.

Median levels of body weight $(p<0.05)$, waist circumference $(p<0.05)$, hip circumference $(p<0.05)$, and waist-to-hip ratio $(p<0.05)$ were higher in depression group (Table 2). 1st- and 2nd-degree obesity were higher in depression group $(27.6 \%$ and $13.8 \%$, resp.) compared to controls $(6.7 \%$ and $0.0 \%$, resp.) $(p<0.05$, Table 3$)$. Median daily energy expenditure of depression group [1946 kcal $(1827-2188 \mathrm{kcal})]$ was lower than of controls [2180 kcal (1944$2470 \mathrm{kcal})](p<0.05)$.

Fasting blood glucose levels $(p<0.05)$ and serum vitamins $B_{12}(p<0.05)$ and folic acid $(p<0.05)$ in depression group were lower than controls. Serum insulin 
TABLE 3: Evaluation of body weight according to body mass index.

\begin{tabular}{|c|c|c|c|c|c|c|}
\hline \multirow[t]{2}{*}{ Body mass index $\left(\mathrm{kg} / \mathrm{m}^{2}\right)$} & \multicolumn{2}{|c|}{$\begin{array}{l}\text { Depression group } \\
\qquad(n=29)\end{array}$} & \multicolumn{2}{|c|}{$\begin{array}{l}\text { Control group } \\
\quad(n=30)\end{array}$} & \multicolumn{2}{|c|}{$\begin{array}{c}\text { Total } \\
(n=59)\end{array}$} \\
\hline & $n$ & $\%$ & $n$ & $\%$ & $n$ & $\%$ \\
\hline Underweight $(<20)$ & 0 & 0.0 & 49 & 13.3 & 4 & 6.8 \\
\hline Normal (20.0-24.9) & 9 & 31.0 & 11 & 36.7 & 20 & 33.9 \\
\hline Overweight (25.0-29.9) & 8 & 27.6 & 13 & 43.3 & 21 & 35.6 \\
\hline 1st-degree obese (30-34.9) & 8 & 27.6 & 2 & 6.7 & 10 & 16.9 \\
\hline 2nd-degree obese (35.0-39.9) & 4 & 13.8 & 0 & 0.0 & 4 & 6.8 \\
\hline 3rd-degree obese (>40) & - & - & - & - & - & - \\
\hline Total & 29 & 100 & 30 & 100 & 59 & 100 \\
\hline
\end{tabular}

$\chi^{2}=12.977 ; p<0.05$.

TABLE 4: Evaluation of biochemical parameters of depression and control groups.

\begin{tabular}{|c|c|c|c|c|}
\hline Biochemical parameters & $\begin{array}{c}\text { Depression group } \\
(n=29) \\
\text { Median } \\
(25 \% \mathrm{p}-75 \% \mathrm{p}) \\
\end{array}$ & $\begin{array}{l}\text { Control group } \\
(n=30) \\
\text { Median } \\
(25 \% \mathrm{p}-75 \% \mathrm{p}) \\
\end{array}$ & $Z$ & $p$ \\
\hline Glucose (mg/dL) & $78.0(72.0-87.0)$ & $86.0(82.7-89.2)$ & -2.559 & $0.010^{*}$ \\
\hline Triglyceride (mg/dL) & $124.0(83.5-168.0)$ & $106.5(63.0-146.7)$ & -1.251 & 0.214 \\
\hline Total cholesterol (mg/dL) & $186.0(165.5-211.5)$ & $188.5(166.2-218.2)$ & -0.159 & 0.877 \\
\hline HDL-C (mg/dL) & $43.0(36.5-54.0)$ & $49.0(41.0-62.0)$ & -1.867 & 0.062 \\
\hline LDL-C (mg/dL) & $116.0(97.5-133.0)$ & $116.5(94.5-145.25)$ & -0.091 & 0.931 \\
\hline Vitamin $B_{12}(\mathrm{pg} / \mathrm{mL})$ & $254.0(203.5-339.0)$ & $324.5(264.0-383.0)$ & -2.153 & $0.031^{*}$ \\
\hline Folate (ng/mL) & $5.12(3.63-6.81)$ & $8.68(6.00-10.10)$ & -3.571 & $<0.001$ \\
\hline Insulin $(\mu \mathrm{U} / \mathrm{mL})$ & $12.5(6.47-33.72)$ & $9.22(5.55-13.27)$ & -1.358 & 0.179 \\
\hline HOMA & $2.45(1.15-8.51)$ & $2.29(1.11-3.10)$ & -0.977 & 0.337 \\
\hline
\end{tabular}

${ }^{*} p<0.05$.

and HOMA levels were not significantly different between groups $(p>0.05)$. Blood lipid levels of both groups were also similar $(p>0.05$, Table 4$)$.

\section{Discussion}

To the best of our knowledge, this is the first study of its kind in Turkey to evaluate nutritional intake, nutritional status, and some biochemical parameters of patients with depression. Results from this study indicated that depressed individuals increase their food intake as a response to negative emotions. Similar to this finding, Konttinen et al. [40] investigated an association between emotional eating and depressive symptoms. Emotional eating was related to higher consumption of sweet foods. In addition, depressive symptoms were related to a lower consumption of vegetables/fruit. We found higher rates of eating at night among patients with depression like Gluck et al. [41].

In this study, similar to previous studies, depressed patients' 24-hour food intake has shown a poor quality diet with lower intake of fruits/vegetables [40, 42]. This association of low fruit/vegetables intake with depression also led to inadequate intake of fibre in this study which is important in healthy life maintenance and protection from diseases [43].
On the other hand, consumption of fish was significantly lower in the depression group compared to controls and these results were consistent with previous studies [44-50]. Fish is the richest source of n-3 PUFA and EPA which has been found to be effective in relieving depression $[49,51]$. Nevertheless, total PUFA intake was not different between people with and without depression in Meyer et al.s study [51]. Similar to Meyer et al. [51], PUFA intake in the present study was similar in depression and control groups.

Intake of a number of nutrients (thiamin, riboflavin, vitamin $\mathrm{B}_{6}$, folate, and $\mathrm{Na}, \mathrm{K}, \mathrm{Mg}, \mathrm{Ca}, \mathrm{P}, \mathrm{Fe}$, and $\mathrm{Zn}$ ) was significantly lower in the depression group compared to controls. Vitamins $\mathrm{C}$ and $\mathrm{A}$ are thought to be effective in depression due to their roles in the oxidative processes $[35,52]$. In this study, patients in the depression group had significantly lower vitamins $\mathrm{C}$ and $\mathrm{A}$ intake than controls and could not meet their requirements according to Dietary Guidelines for Turkey. Similar to this study, Oishi et al. [53] indicated negative association between depressive symptoms and carotene and vitamin $\mathrm{C}$ intakes.

Folate and vitamin $B_{12}$ are necessary for normal functioning of nervous system. They are also required for single carbon metabolism responsible for synthesis and metabolism of serotonin and other neurotransmitters [35]. All B vitamins 
work as a cofactor of the key enzymes for neurotransmitter production and to control their balance [54]. Similar to the present study, Pellegrin et al. [55] reported a low level of folate intake in depressed patients. Furthermore, depressed patients consumed less thiamine, riboflavin, and vitamin $\mathrm{B}_{6}$ than controls which show the overall inadequate intake of $B$ vitamins in this study. In the Coronary Health Improvement Project (CHIP), conducted to decrease depression by modifying selected daily nutrients from food, a decrease in depression was achieved by increasing pyridoxine. [56].

Magnesium deficiency is known to cause neuropathologies. Lack of $\mathrm{Mg}$ leads to depression because of neuron damage occurring as a result of not meeting the $\mathrm{Mg}$ requirement of neurons [57]. Magnesium intake of the depression group in the present study was significantly lower than controls which may be due to insufficient consumption of food resources of $\mathrm{Mg}$ such as red meat, oilseeds, and nuts.

Inadequate dietary $\mathrm{Zn}$ and Fe intake contribute to depressive symptoms $[35,58,59]$. It was found in the present study that depression group consumed significantly lower amounts of Fe and $\mathrm{Zn}$ compared with controls, which may have resulted from low consumption of oil seeds.

Biological factors in depression occurrence are electrolyte imbalances especially $\mathrm{Na}$ and $\mathrm{K}$, neurophysiological changes, autonomous nervous system dysfunction, and neuroendocrinological disorders in gonads, thyroid, hypophysis, adrenal cortex, and hypothalamus [60]. The present study findings demonstrated that depressed patients consumed lower amounts of $\mathrm{Na}, \mathrm{K}, \mathrm{Ca}$, and $\mathrm{P}$ than controls.

The majority of literature demonstrates high prevalence of depression in people with high BMI [61-66]. It is still not clear whether depression leads to obesity in response to changing appetite and medicines or obesity contributes to depressive disturbances. Consistent with the literature findings, median body weight $(\mathrm{kg})$ and BMI $\left(\mathrm{kg} / \mathrm{m}^{2}\right)$ of the depression group were significantly higher than controls in our study. Waist and hip circumferences and waist-tohip ratios which show body fat distribution are important because chronic diseases, symptoms, and low quality of life are affected [67]. In a study conducted with 3186 adult males and 3003 adult females, depressed participants were found to have higher waist circumferences [68]. Besides body weight and BMI, we have found that waist-hip circumferences and waist-to-hip ratios were higher in patients with depression compared to controls.

High incidence of folic acid deficiency has been shown in patients with depression [45, 69-71]. The present study demonstrated lower serum folic acid levels in the depression group compared to controls, which may have resulted from low dietary folate consumption of the depressed patients. Vitamin $B_{12}$ deficiency independently stimulates tetrahydrobiopterin production, retards monoamine neurotransmitters, and may cause functional folate deficiency [72]. In one study, people with vitamin $B_{12}$ deficiency were found to have 2.05 times the risk of depression [73]. However, another study failed to show a significant difference between mean serum vitamin $B_{12}$ levels of the depression and control groups [69]. In addition to these conflicting findings, the depression group in our study was found to have significantly lower serum levels of vitamin $\mathrm{B}_{12}$ compared to controls.

Depression is a symptom of impaired blood glucose tolerance [54]. One study demonstrated that depression in women was significantly related to increased blood glucose levels [74]. Conversely, in the present study, the median fasting blood glucose levels of the depression group were significantly lower compared to controls; however the fasting blood glucose levels of both groups were in normal range.

Depression is associated with an increased risk of incident diabetes; insulin resistance is thought to be the underlying link between them. Nevertheless, only a few studies have explored the association between insulin resistance and depression, with contradictory results [75-77]. A weak and positive correlation has been reported between scores identifying depression and HOMA-IR score [76, 77]. It was determined in the present study that HOMA was insignificantly higher in the depression group compared to controls with no insulin resistance in either group.

In this study, there are some limitations, the first of which is our small sample size. Large-scale studies are needed on this issue in the future studies. Second, self-reported dietary intake data are likely inaccurate.

\section{Conclusion}

Patients with depression were found to consume a poor quality diet which is known to lead to depressive symptoms. Besides low intake of some B vitamins, serum levels of vitamin $\mathrm{B}_{12}$ and folic acid were low, and there were many signs of abdominal obesity in the depression group. Therefore, future research exploring the overall nutritional status of individuals with depression is warranted in order to assist in understanding and treatment of the condition and to promote healthy lifestyles that may help in depression management.

\section{Relevance to Clinical Practice}

By investigating nutritional status and dietary intake of patients with depression and providing adequate-balanced nutrition, healthcare professionals may contribute to the therapy of patients in the clinic.

\section{Disclosure}

This paper has been presented at ESPEN congress as an abstract.

\section{Conflict of Interests}

No conflict of interests is declared.

\section{Authors' Contribution}

Nimet Yüksel and Neriman Inanç designed the study; Nimet Yüksel collected the data; Gülşah Kaner, Meltem Soylu, and Dilek Ongan prepared the paper. 


\section{Acknowledgment}

The authors acknowledge Gökmen Zararsız for statistical data analysis in Erciyes University.

\section{References}

[1] WHO, Mental Health Action Plan 2013-2020, World Health Organization, Geneva, Switzerland, 2013.

[2] N. Sugawara, N. Yasui-Furukori, S. Tsuchimine et al., "No association between dietary patterns and depressive symptoms among a community-dwelling population in Japan," Annals of General Psychiatry, vol. 11, article 24, 2012.

[3] E. Mamplekou, V. Bountziouka, T. Psaltopoulou et al., "Urban environment, physical inactivity and unhealthy dietary habits correlate to depression among elderly living in eastern mediterranean islands: the MEDIS (Mediterranean Islands Elderly) study," Journal of Nutrition, Health and Aging, vol. 14, no. 6, pp. 449-455, 2010.

[4] A. Sánchez-Villegas, M. Delgado-Rodríguez, A. Alonso et al., "Association of the Mediterranean dietary pattern with the incidence of depression: the Seguimiento Universidad de Navarra/University of Navarra follow-up (SUN) cohort," Archives of General Psychiatry, vol. 66, no. 10, pp. 1090-1098, 2009.

[5] F. N. Jacka, P. J. Kremer, E. R. Leslie et al., "Associations between diet quality and depressed mood in adolescents: results from the Australian Healthy Neighbourhoods Study," Australian and New Zealand Journal of Psychiatry, vol. 44, no. 5, pp. 435-442, 2010.

[6] L. German, C. Kahana, V. Rosenfeld et al., "Depressive symptoms are associated with food insufficiency and nutritional deficiencies in poor community-dwelling elderly people," Journal of Nutrition, Health and Aging, vol. 15, no. 1, pp. 3-8, 2011.

[7] R. W. Jeffery, J. A. Linde, G. E. Simon et al., "Reported food choices in older women in relation to body mass index and depressive symptoms," Appetite, vol. 52, no. 1, pp. 238-240, 2009.

[8] A. Sánchez-Villegas, E. Toledo, J. de Irala, M. Ruiz-Canela, J. Pla-Vidal, and M. A. Martínez-González, "Fast-food and commercial baked goods consumption and the risk of depression," Public Health Nutrition, vol. 15, no. 3, pp. 424-432, 2012.

[9] T. Ciarambino, N. Ferrara, P. Castellino, G. Paolisso, L. Coppola, and M. Giordano, "Effects of a 6-days-a-week low protein diet regimen on depressive symptoms in young-old type 2 diabetic patients," Nutrition, vol. 27, no. 1, pp. 46-49, 2011.

[10] G. D. Brinkworth, J. D. Buckley, M. Noakes, P. M. Clifton, and C. J. Wilson, "Long-term effects of a very low-carbohydrate diet and a low-fat diet on mood and cognitive function," Archives of Internal Medicine, vol. 169, no. 20, pp. 1873-1880, 2009.

[11] P.-Y. Lin, S.-Y. Huang, and K.-P. Su, "A meta-analytic review of polyunsaturated fatty acid compositions in patients with depression," Biological Psychiatry, vol. 68, no. 2, pp. 140-147, 2010.

[12] M. E. Sublette, S. P. Ellis, A. L. Geant, and J. J. Mann, "Metaanalysis of the effects of eicosapentaenoic acid (EPA) in clinical trials in depression," Journal of Clinical Psychiatry, vol. 72, no. 12, pp. 1577-1584, 2011.

[13] A. Farah, "The role of L-methylfolate in depressive disorders," CNS Spectrums, vol. 14, no. 1, pp. 2-7, 2009.

[14] D. W. Morris, M. H. Trivedi, and A. J. Rush, "Folate and unipolar depression," Journal of Alternative and Complementary Medicine, vol. 14, no. 3, pp. 277-285, 2008.
[15] E. C. Cope and C. W. Levenson, "Role of zinc in the development and treatment of mood disorders," Current Opinion in Clinical Nutrition and Metabolic Care, vol. 13, no. 6, pp. 685689, 2010.

[16] J. Lai, A. Moxey, G. Nowak, K. Vashum, K. Bailey, and M. McEvoy, "The efficacy of zinc supplementation in depression: systematic review of randomised controlled trials," Journal of Affective Disorders, vol. 136, no. 1-2, pp. e31-e39, 2012.

[17] B. Szewczyk, M. Kubera, and G. Nowak, "The role of zinc in neurodegenerative inflammatory pathways in depression," Progress in Neuro-Psychopharmacology and Biological Psychiatry, vol. 35, no. 3, pp. 693-701, 2011.

[18] R. Stewart and V. Hirani, "Relationship between depressive symptoms, anemia, and iron status in older residents from a national survey population," Psychosomatic Medicine, vol. 74, no. 2, pp. 208-213, 2012.

[19] M. V. Shariatpanaahi, Z. V. Shariatpanaahi, M. Moshtaaghi, S. H. Shahbaazi, and A. Abadi, "The relationship between depression and serum ferritin level," European Journal of Clinical Nutrition, vol. 61, no. 4, pp. 532-535, 2007.

[20] C. Merete, L. M. Falcon, and K. L. Tucker, "Vitamin B6 is associated with depressive symptomatology in Massachusetts elders," Journal of the American College of Nutrition, vol. 27, no. 3, pp. 421-427, 2008.

[21] D. Moorthy, I. Peter, T. M. Scott et al., "Status of vitamins $B_{12}$ and $\mathrm{B}_{6}$ but not of folate, homocysteine, and the methylenetetrahydrofolate reductase C677T polymorphism are associated with impaired cognition and depression in adults," Journal of Nutrition, vol. 142, no. 8, pp. 1554-1560, 2012.

[22] K. A. Skarupski, C. Tangney, H. Li, B. Ouyang, D. A. Evans, and M. C. Morris, "Longitudinal association of vitamin B-6, folate, and vitamin B-12 with depressive symptoms among older adults over time," American Journal of Clinical Nutrition, vol. 92, no. 2, pp. 330-335, 2010.

[23] J. Hintikka, T. Tolmunen, A. Tanskanen, and H. Viinamäki, "High vitamin $\mathrm{B}_{12}$ level and good treatment outcome may be associated in major depressive disorder," BMC Psychiatry, vol. 3, article 17, 2003.

[24] J. Raman, E. Smith, and P. Hay, "The clinical obesity maintenance model: an integration of psychological constructs including mood, emotional regulation, disordered overeating, habitual cluster behaviours, health literacy and cognitive function," Journal of Obesity, vol. 2013, Article ID 240128, 9 pages, 2013.

[25] C. U. Onyike, R. M. Crum, H. B. Lee, C. G. Lyketsos, and W. W. Eaton, "Is obesity associated with major depression? Results from the Third National Health and Nutrition Examination Survey," American Journal of Epidemiology, vol. 158, no. 12, pp. 1139-1147, 2003.

[26] R. E. Roberts, G. A. Kaplan, S. J. Shema, and W. J. Strawbridge, "Are the obese at greater risk for depression?" American Journal of Epidemiology, vol. 152, no. 2, pp. 163-170, 2000.

[27] R. E. Roberts, W. J. Strawbridge, S. Deleger, and G. A. Kaplan, "Are the fat more jolly?" Annals of Behavioral Medicine, vol. 24, no. 3, pp. 169-180, 2002.

[28] K. M. Carpenter, D. S. Hasin, D. B. Allison, and M. S. Faith, "Relationships between obesity and DSM-IV major depressive disorder, suicide ideation, and suicide attempts: results from a general population study," American Journal of Public Health, vol. 90, no. 2, pp. 251-257, 2000. 
[29] T. Hällström and H. Noppa, "Obesity in women in relation to mental illness, social factors and personality traits," Journal of Psychosomatic Research, vol. 25, no. 2, pp. 75-82, 1981.

[30] L. A. Palinkas, D. L. Wingard, and E. Barrett-Connor, "Depressive symptoms in overweight and obese older adults: a test of the 'jolly fat' hypothesis,' Journal of Psychosomatic Research, vol. 40, no. 1, pp. 59-66, 1996.

[31] M. Faubel, "Body image and depression in women with early and late onset obesity," The Journal of Psychology: Interdisciplinary and Applied, vol. 123, no. 4, pp. 385-395, 1989.

[32] D. A. Grossniklaus, S. B. Dunbar, R. Gary, B. C. Tohill, J. K. Frediani, and M. K. Higgins, "Dietary energy density: a mediator of depressive symptoms and abdominal obesity or independent predictor of abdominal obesity?" European Journal of Cardiovascular Nursing, vol. 11, no. 4, pp. 423-431, 2012.

[33] G. Zhao, E. S. Ford, C. Li, J. Tsai, S. Dhingra, and L. S. Balluz, "Waist circumference, abdominal obesity, and depression among overweight and obese U.S. adults: national health and nutrition examination survey 2005-2006," BMC Psychiatry, vol. 11, article 130, 2011.

[34] B. M. Appelhans, M. C. Whited, K. L. Schneider et al., "Depression severity, diet quality, and physical activity in women with obesity and depression," Journal of the Academy of Nutrition and Dietetics, vol. 112, no. 5, pp. 693-698, 2012.

[35] L. M. Bodnar and K. L. Wisner, "Nutrition and depression: implications for improving mental health among childbearingaged women," Biological Psychiatry, vol. 58, no. 9, pp. 679-685, 2005.

[36] WHO Technical Report Series (WHO), "Physical status: the use and interpretation of anthropometry," Report of a WHO Expert Committee 854, World Health Organization, Geneva, Switzerland, 1995.

[37] A. Baysal, M. Aksoy, N. Bozkurt et al., Diyet El Kitabı, Beslenme Durumunun Saptanması, Hatiboğlu Yayınevi, Ankara, Turkey, 4th edition, 2002 (Turkish).

[38] The Ministry of Health of Turkey and The General Directorate of Primary Health Care, Dietary Guidelines for Turkey (2006) Recommended Safe Level of Intake of Energy and Nutrients for Turkey, The Ministry of Health of Turkey, The General Directorate of Primary Health Care, Ankara, Turkey, 2013, http://www.bdb.hacettepe.edu.tr/dokumanlar/dietaryguidelines.pdf.

[39] N. Rakıcıoğlu, N. Tek Acar, A. Ayaz, and G. Pekcan, Yemek ve Besin Fotoğraf Kataloğu-Ölçü ve Miktarlar, Ata Ofset Matbaacilık, Ankara, Turkey, 2nd edition, 2009, (Turkish).

[40] H. Konttinen, S. Männistö, S. Sarlio-Lähteenkorva, K. Silventoinen, and A. Haukkala, "Emotional eating, depressive symptoms and self-reported food consumption. A populationbased study," Appetite, vol. 54, no. 3, pp. 473-479, 2010.

[41] M. E. Gluck, A. Geliebter, and T. Satov, "Night eating syndrome is associated with depression, low self-esteem, reduced daytime hunger, and less weight loss in obese outpatients," Obesity Research, vol. 9, no. 4, pp. 264-267, 2001.

[42] C. Liu, B. Xie, C.-P. Chou et al., "Perceived stress, depression and food consumption frequency in the college students of China seven cities," Physiology \& Behavior, vol. 92, no. 4, pp. 748-754, 2007.

[43] G. Samur and S. M. Mercanligil, Diyet posası ve beslenme, The Ministry of Health of Turkey, The General Directorate of Primary Health Care, 2008 (Turkish).
[44] J. K. Kiecolt-Glaser, M. A. Belury, K. Porter, D. Q. Beversdorf, S. Lemeshow, and R. Glaser, "Depressive symptoms, omega6: omega-3 fatty acids, and inflammation in older adults," Psychosomatic Medicine, vol. 69, no. 3, pp. 217-224, 2007.

[45] W. Kohatsu, "Nutrition and Depression," Explore, vol. 1, no. 6, pp. 474-476, 2005.

[46] H. H. Atar and Z. Alçiçek, "Seafood consumption and health," TAF Preventive Medicine Bulletin, vol. 8, no. 2, pp. 173-176, 2009.

[47] A. Tanskanen, J. R. Hibbeln, J. Tuomilehto et al., "Fish consumption and depressive symptoms in the general population in Finland," Psychiatric Services, vol. 52, no. 4, pp. 529-531, 2001.

[48] S. Noaghiul and J. R. Hibbeln, "Cross-national comparisons of seafood consumption and rates of bipolar disorders," The American Journal of Psychiatry, vol. 160, no. 12, pp. 2222-2227, 2003.

[49] M. Timonen, D. Horrobin, J. Jokelainen, J. Laitinen, A. Herva, and P. Räsänen, "Fish consumption and depression: the Northern Finland 1966 birth cohort study," Journal of Affective Disorders, vol. 82, no. 3, pp. 447-452, 2004.

[50] Y. Li, Q. Dai, L. I. Ekperi, A. Dehal, and J. Zhang, "Fish consumption and severely depressed mood, findings from the first national nutrition follow-up study," Psychiatry Research, vol. 190, no. 1, pp. 103-109, 2011.

[51] B. J. Meyer, N. Kolanu, D. A. Griffiths, B. Grounds, P. R. C. Howe, and I. A. Kreis, "Food groups and fatty acids associated with self-reported depression: an analysis from the Australian National Nutrition and Health Surveys," Nutrition, vol. 29, no. 7-8, pp. 1042-1047, 2013.

[52] A. F. Jorm, H. Christensen, K. M. Griffiths, and B. Rodgers, "Effectiveness of complementary and self-help treatments for depression," Medical Journal of Australia, vol. 176, pp. S84-S96, 2002.

[53] J. Oishi, H. Doi, and N. Kawakami, "Nutrition and depressive symptoms in community-dwelling elderly persons in Japan," Acta Medica Okayama, vol. 63, no. 1, pp. 9-17, 2009.

[54] P. Holford, “Depression: the nutrition connection," Primary Care Mental Health, vol. 1, pp. 9-16, 2003.

[55] K. L. Pellegrin, P. M. O’Neil, E. J. Stellefson et al., "Average daily nutrient intake and mood among obese women," Nutrition Research, vol. 18, no. 7, pp. 1103-1112, 1998.

[56] R. M. Merrill, P. Taylor, and S. G. Aldana, "Coronary Health Improvement Project (CHIP) is associated with improved nutrient intake and decreased depression," Nutrition, vol. 24, no. 4, pp. 314-321, 2008.

[57] G. A. Eby and K. L. Eby, "Rapid recovery from major depression using magnesium treatment," Medical Hypotheses, vol. 67, no. 2, pp. 362-370, 2006.

[58] N. N. Maserejian, S. A. Hall, and J. B. McKinlay, "Low dietary or supplemental zinc is associated with depression symptoms among women, but not men, in a population-based epidemiological survey," Journal of Affective Disorders, vol. 136, no. 3, pp. 781-788, 2012.

[59] S. M. Lehto, A. Ruusunen, T. Tolmunen, S. Voutilainen, T.P. Tuomainen, and J. Kauhanen, "Dietary zinc intake and the risk of depression in middle-aged men: a 20 -year prospective follow-up study," Journal of Affective Disorders, vol. 150, no. 2, pp. 682-685, 2013.

[60] N. Ören and B. Gençdoğan, "Lise öğrencilerinin depresyon düzeylerinin bazı değişkenlere göre incelenmesi," Kastamonu Ĕ̈itim Dergisi, vol. 1, pp. 85-92, 2007 (Turkish). 
[61] A. J. Stunkard, M. S. Faith, and K. C. Allison, "Depression and obesity," Biological Psychiatry, vol. 54, no. 3, pp. 330-337, 2003.

[62] J. Ma and L. Xiao, "Obesity and depression in US woman: results from the 2005-2006 National Health and Nutritional Examination Survey," Obesity, vol. 18, no. 2, pp. 347-353, 2010.

[63] J. M. Murphy, N. J. Horton, J. D. Burke Jr. et al., "Obesity and weight gain in relation to depression: findings from the Stirling County study," International Journal of Obesity, vol. 33, no. 3, pp. 335-341, 2009.

[64] G. E. Simon, E. J. Ludman, J. A. Linde et al., "Association between obesity and depression in middle-aged women," General Hospital Psychiatry, vol. 30, no. 1, pp. 32-39, 2008.

[65] P. Ravasco, J. Correia, M. Chaves, and M. Camilo, "Depression and nutrition: a complex association," Clinical Nutrition Supplements, vol. 5, no. 2, pp. 143-144, 2010.

[66] L. de Wit, F. Luppino, A. van Straten, B. Penninx, F. Zitman, and P. Cuijpers, "Depression and obesity: a meta-analysis of community-based studies," Psychiatry Research, vol. 178, no. 2, pp. 230-235, 2010.

[67] H. Yardımcı and A. Ö. Özçelik, Ankara ili gölbaşı ilçesinde yetişkin kadınların antropometrik ölçümleri ve beslenme alışkanlıkları üzerinde bir araştırma [Doktora Tezi], Ankara Üniversitesi Fen Bilimleri Enstitüsü, Ankara, Turkey, 2006, (Turkish).

[68] L. S. Kinder, M. R. Carnethon, L. P. Palaniappan, A. C. King, and S. P. Fortmann, "Depression and the metabolic syndrome in young adults: findings from the Third National Health and Nutrition Examination Survey," Psychosomatic Medicine, vol. 66, no. 3, pp. 316-322, 2004.

[69] T. Bottiglieri, M. Laundy, R. Crellin, B. K. Toone, M. W. P. Carney, and E. H. Reynolds, "Homocysteine, folate, methylation, and monoamine metabolism in depression," Journal of Neurology Neurosurgery \& Psychiatry, vol. 69, no. 2, pp. 228232, 2000.

[70] C. Lazarou and M. Kapsou, "The role of folic acid in prevention and treatment of depression: an overview of existing evidence and implications for practice," Complementary Therapies in Clinical Practice, vol. 16, no. 3, pp. 161-166, 2010.

[71] E. H. Reynolds, "Benefits and risks of folic acid to the nervous system," Journal of Neurology Neurosurgery and Psychiatry, vol. 72, no. 5, pp. 567-571, 2002.

[72] H. Tiemeier, H. Ruud van Tuijl, A. Hofman, J. Meijer, A. J. Kiliaan, and M. M. B. Breteler, "Vitamin $B_{12}$, folate, and homocysteine in depression: the Rotterdam study," American Journal of Psychiatry, vol. 159, no. 12, pp. 2099-2101, 2002.

[73] B. W. J. H. Penninx, J. M. Guralnik, L. Ferrucci, L. P. Fried, R. H. Allen, and S. P. Stabler, "Vitamin $\mathrm{B}_{12}$ deficiency and depression in physically disabled older women: epidemiologic evidence from the women's health and aging study," The American Journal of Psychiatry, vol. 157, no. 5, pp. 715-721, 2000.

[74] S. Toker, A. Shirom, and S. Melamed, "Depression and the metabolic syndrome: gender-dependent associations," Depression and Anxiety, vol. 25, no. 8, pp. 661-669, 2008.

[75] A. Pan, X. Ye, O. H. Franco et al., "Insulin resistance and depressive symptoms in middle-aged and elderly Chinese: findings from the Nutrition and Health of Aging Population in China Study," Journal of Affective Disorders, vol. 109, no. 1-2, pp. 75-82, 2008.

[76] M. Timonen, M. Laakso, J. Jokelainen, U. Rajala, V. B. MeyerRochow, and S. Keinänen-Kiukaanniemi, "Insulin resistance and depression: cross sectional study," British Medical Journal, vol. 330, no. 7481, pp. 17-18, 2005.
[77] M. C. Adriaanse, J. M. Dekker, G. Nijpels, R. J. Heine, F. J. Snoek, and F. Pouwer, "Associations between depressive symptoms and insulin resistance: the Hoorn study," Diabetologia, vol. 49, no. 12, pp. 2874-2877, 2006. 


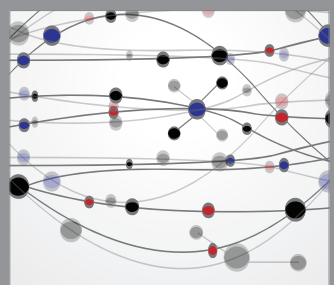

The Scientific World Journal
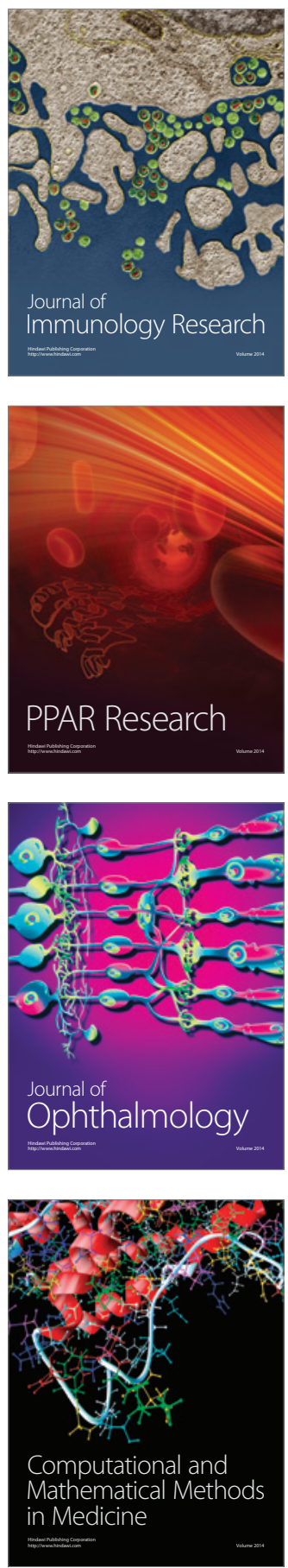

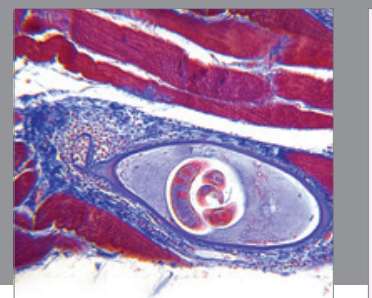

Gastroenterology

Research and Practice
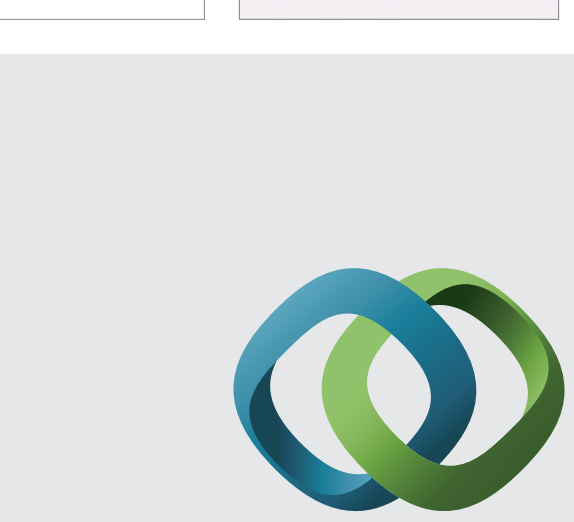

\section{Hindawi}

Submit your manuscripts at

http://www.hindawi.com
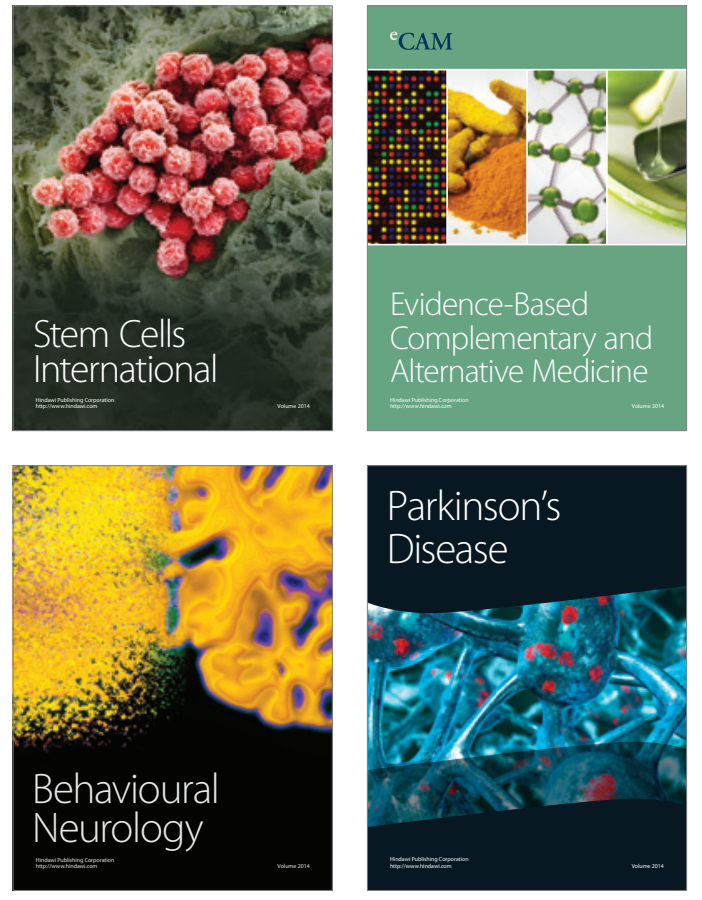
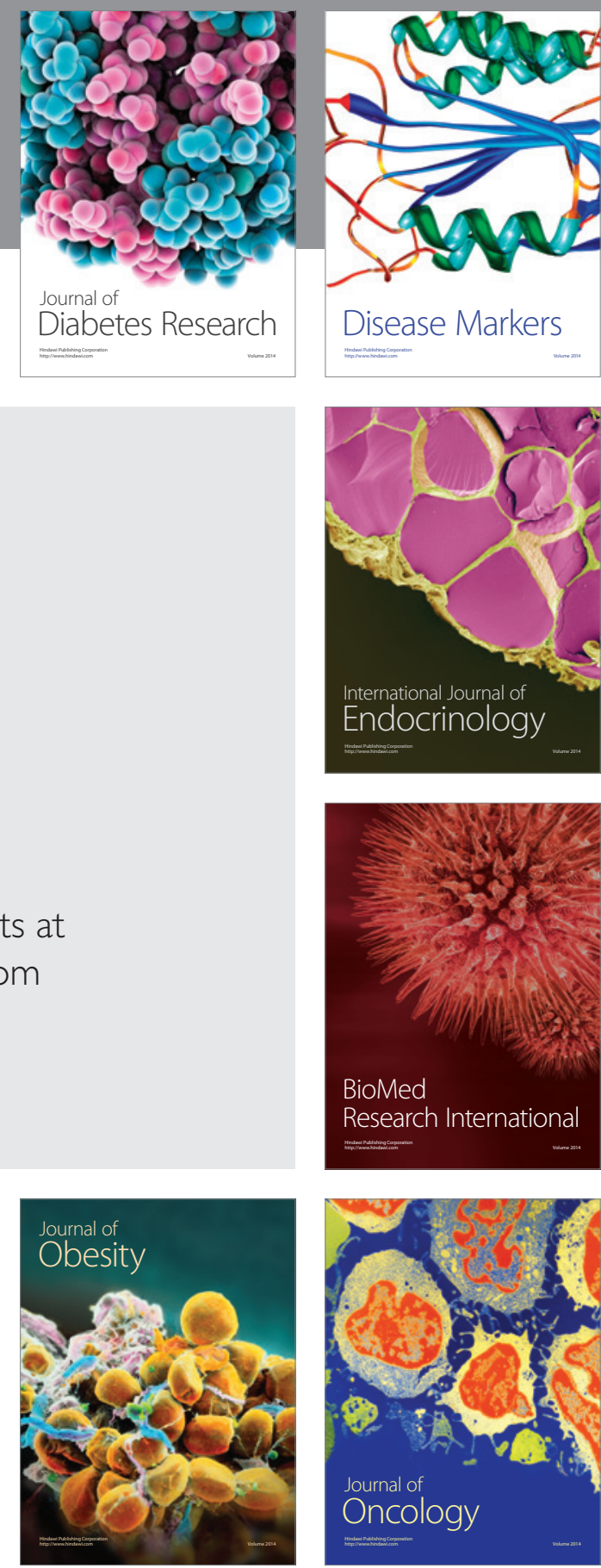

Disease Markers
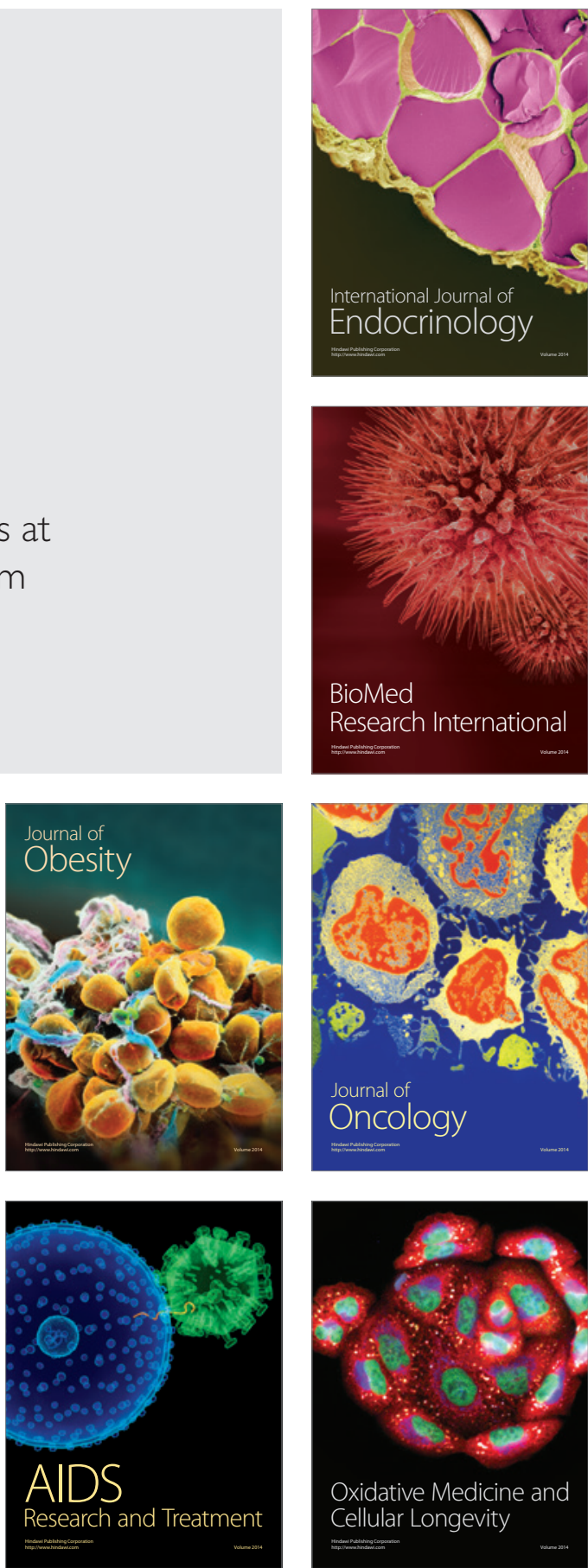